\title{
COPIM•
}

\section{Part 1: Interaction in Context}

Janneke Adema, Sam Moore, Tobias Steiner

Published on: Oct 21, 2021

License: Creative Commons Attribution 4.0 International License (CC-BY 4.0). 


\section{Open Annotation}

Web-based annotations of digital books enrich a scholarly text through overlays and filters that sit on top of the text in order to show additional commentary and feedback. Annotations-in short, a form of readerly or writerly interaction that consists of notes (in any medium) added to texts (of any medium) 1 -already have a long history in a print and manuscript context (e.g., marginalia, errata, rubrics), but the immediacy of two-way discussion between users is a notable feature of digital open annotations, both of comments at the bottom of a text and in-line text annotations. Bertino and Staines therefore liken annotation to a "conversation" between authors and audiences that was previously much less interactive Bertino \& Staines, 2019. In addition to this, for Tara McPherson annotations (of e.g., digital visual archives) may also facilitate a more "seamless integration of research materials and scholarly analysis" through a closer presentation between commentary and the object studied (McPherson, 2010). This is particularly useful in a scholarly communication environment where annotations enable discussions to take place in direct proximity to the material that is under consideration, for example with linguistic markup of text corpora.

Open online annotation fulfils several functions that can be beneficial for scholarly communication. Kalir and Garcia summarise the common purposes of annotation quite succinctly: "to provide information, to share commentary, to spark conversation, to express power, and to aid learning” Kalir \& Garcia, 2021. Bertino and Staines mention that in addition to enabling collaborations and the opportunity to engage more directly with authors atop of research materials, open annotation allows feedback from readers, corrections and updates, enables inline (open) peer review, augmentation of publications with additional (multimedia) information, connections to related resources, further context around citations, and it offers opportunities within pedagogical settings. $\underline{2}$ They also point out that, beyond human generated annotations, there are also opportunities to enhance content through auto-generated annotations which, as they state, "might include additional information around identifiers, controlled vocabulary, or recommendations" Bertino \& Staines, 2019. In this context they explain that there are also opportunities for various semantic applications where the open annotation of documents allows annotations to be "searchable by tags that make it possible to identify

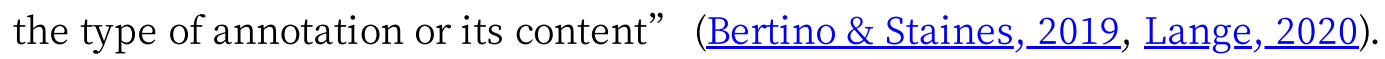

In 2017, the World Wide Web Consortium (W3C), the standards body for the web, published its recommended standards for web annotation in order to create, organise, 
and share annotations in an open way (previous annotation systems were often proprietary and closed). Their vision is for a standards-based, decentralised, and open interoperable, annotation infrastructure where open web annotation "can be linked, shared between services, tracked back to their origins, searched and discovered, and stored wherever the author wishes." $\underline{3}$ The Hypothes.is organisation-which designs annotation overlays for the Web-likens this standard, in which an annotation will be a web document itself, identified with its own URI (i.e., as they say "separating discussion about a page from the page itself" ) to "democratisation" whereby users are able to share their direct comments on a publication for all to see, without permission from website gatekeepers (van den Broeke, 2014).

This speaks of the participatory approach to annotated content and its potential to undermine traditional notions of proprietary authorship and authorial control over open content. Cameron Neylon describes the potential of annotation in terms of a placing the "document" , rather than the author, at the centre of attention in a way that allows the content to evolve over time based on a range of author-reader interactions (Perkel, 2015). Annotation, and collaborative writing more generally, are also what Montgomery et al. describe in the introduction to their book Open Knowledge Institutions as an opportunity to "socialize the process of knowledge creation" by extending the "collaborative spirit" from authorship out to review and revision (Montgomery et al.,2018). There is thus an interesting interplay within open annotation between its ability to simultaneously foreground social processes of authorship while also questioning the very nature of authorial authority.

For Janneke Adema for example, annotation has the ability to enrich a document through its ability to "interweave" itself with the other voices in a project, thus presenting a textured, multi-perspective publication in one document (Adema, 2018:72). But at the same time, for Adema, annotation poses questions about where the document actually begins and ends. ${ }^{4}$ Drawing on Derrida, she poses questions about how to locate the text itself once it has been annotated: "as Derrida has argued, writing in the margins-where the margin more in general takes in a liminal inside/outside position-forms a means of resistance, a disruption or blurring of the line between the central main text and the writing in the margins" (Adema, 2018:72). Annotation therefore points to a level of liquidity and intertextuality within a publication that disrupts what it means to have a fixed and final publication.

Rather than taking an understanding of annotation as revolutionary, some researchers of annotations have situated it as part of a continuation of the traditional standards of print 
publishing. For example, Kalir and Dean argue that although there may be "social, technical or political" implications of annotations for scholarship, these are ultimately "amplifications of traditional media practices" rather than entirely unique practices. Given this, annotation of scholarship simply "complements everyday activities associated with mediated information literacy, such as how people access media, curate resources, converse, and critique ideas and power" (2017). As Kalir and Garcia argue therefore, annotation is essential to developing knowledge communities, where collaborative annotation technologies and practices are seen as an important social practice within these communities "to make their research processes more transparent, to participate in peer review, and to communicate with various publics" (Kalir \& Garcia, 2019). Kalir and Dean see annotation as a chance to fully explore the possible democratisation of media, rather than simply assuming that annotation leads to democratisation. They therefore see annotation as performative in the sense that it both "accentuates and helps record a number of distinctive and salient qualities about performance in scholarly production and interaction” (2017), such as authorship, peer review, and fixity (among others). Annotation does not presuppose any specific practice, then, but may allow us to stretch the limits of certain taken-for-granted practices in scholarly publishing.

For example, through exploring the technical capacities of the born-digital monograph, Humphreys et al. show how notions of private note-taking can be upended through annotations. Marginalia, as mentioned above, is traditionally a deeply personal act whereby the reader describes their thoughts without an external reader in mind (Humphreys et al.,2018). But through digital technologies, readers are now able to export, share, and preserve their annotations for a range of audiences. It is perhaps worth mentioning the project Derrida's Margins at this juncture, a project by Katie Chenoweth to transform Derrida' s personal marginalia (including post-it notes, bookmarks, index cards, and correspondence notes) into publicly-accessible annotations (Derrida's Margins, 2018). Alongside exploring this tension between public and private, Derrida's Margins highlights the technical affordances of the digital to reimagine the physicality not just of a book but of an author' s personal library too. $\underline{5}$ There is thus a material component that experimental publishing through annotations sheds light on.

As Kalir and Garcia note though, the power relations that determine who can and does write annotations and who can' t and don' $\mathrm{t}$ (who gets to annotate) "is bound by social norms, cultural practices, and enforced policies" , which needs to be taken into consideration when we think about how we can cultivate participation and interaction around texts, especially within a scholarly communications realm Kalir \& Garcia, 2021. 
This might explain why, as Lyle Skains sets out, notwithstanding several trials in the humanities, annotation as a form of public discourse "has not been a resoundingly successful venture" in these fields Skains, 2020. As Skains outlines, the culture of academia is to blame, which they summarise as "fears about being 'scooped' , about blowback, about domineering commenters, and lack of time coalesce to result in extremely poor participation in this emerging form of discourse." In particular "time, effort, and accessibility" become barriers to participation in this form of academic engagement, especially in a context where annotations usually cannot be cited, which means that in the scholarly reward and reputation system "they offer no verifiable benefit to the contributor in either cultural capital or actual capital" (kkains, 2020,

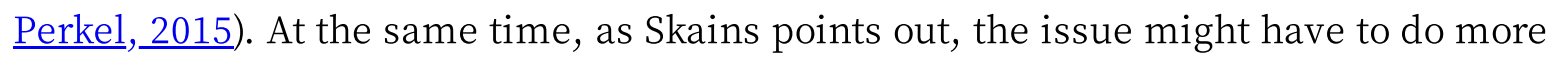
with how publications themselves are perhaps not the best "platforms for interaction" because there is already ubiquitous social media (such as Twitter and mailing lists) on which publications are shared and discussions around them take place (next to our already established print-based environments dedicated to discussing books and research, e.g., conferences and book reviews). In this sense as scholars such as Skains and Faulkes argue, why would scholars duplicate that effort for specific platforms or on specific publications with more restricted audiences, with limited visibility, and with no benefit to their standing or career? (ㅈalkes, 2014, $\underline{\text { Skains, 2020) }}$

To ensure annotations are citable research outputs, Bertino and Staines outline how preservation is both crucial and a challenge, as it should include clear practices around "storing annotations, sharing annotations, and reusing annotations." As they explain, certain organisations or knowledge communities would want to hosts annotations on their own servers (for example in hypothes.is they are by default stored on the hypothes.is servers), which is already being explored by some publishers. $\underline{6}$ Similarly, discoverability of annotations remains an issue, where wider discoverability might to some extent address the issue Skains mentioned around the trouble with creating publics around texts. As Bertino and Staines explain, within the HIRMEOS project they worked on enhanced discoverability options for annotations made through hypothes.is. With HIRMEOS' Annotation Service, “annotations made on content that has a digital object identifier (DOI) or that refer to content that has a DOI (or both), are shared with Crossref Event Data for indexing by Google and end user discovery. This expands the visibility of annotations and their associated content beyond the immediate context of the annotator, making them part of a wider scholarly communication infrastructure and again placing them in the context of FAIR data” Bertino \& Staines, 2019. 
In this respect, the promise of a platform such as hypothes.is, and with that for the uptake of digital marginalia, is exactly its ubiquity. In addition to that, what makes this system potentially attractive to scholars is its options for, as Skains states "anonymity (and conversely, identification), permanent discourse records, public and private options, in-text linking, and the ability to toggle the overlay on and off" (․kains, 2020). The issue of anonymity comes with both drawbacks and benefits though. As Skains explains it, where anonymity can stimulate participation (for example in peer review contexts where there is an imbalance of power), identification "encourages tactful participation" . For scholars, identification, plus the ability to cite or have a permanent record of discourse in the form of annotations, (i.e., permanent, identifiable, citable - or published - records) can be helpful for one' s standing in the field, for career progress, and for impact statements.

To ensure the power imbalances in open annotation do not lead to bullying, spam, microaggressions, or the domineering of certain voices, moderation of comments and annotations will be crucial, as well as-in certain academic settings-code of conducts or clear instructions for interaction. Kalir and Garcia outline how organisations such as Hypothes.is have been involved in facilitating conversations around " 'Consent and Abuse in Annotation Systems,' with recommendations that include developing opt-out technologies for authors and strategies that balance author preferences with the public interest" (Kalir \& Garcia, 2021, Whaley,_2016, Gunn, 2016). There is a balance to be struck here between respecting "both authors' ability to control how their content is annotated and the freedom of speech that protects annotation" (ㅁyson, 2017). where many authors also see annotation as "intrusive" . . Similarly annotation can both designate which voices get to count (i.e., further inscribing already dominant voices) as well as expand which voices count within a given discourse (e.g., by opening up scholarly discourses for wider public participation).

Increasingly publishers are accommodating annotation either on top of their open collections or on specific open titles, and annotations (either in the authoring environment or the reading environment) are also becoming a standard feature of longform publishing platforms, from CommentPress to Manifold, Scalar, and PubPub. One example of a press that has tried to accommodate annotation and conversation on some of its open access books is the MIT Press, who has been releasing various open access titles, for example from its MIT Press Open collection, on the PubPub platform to open them up for annotation and pre- or post-publication feedback. Part of this is done via their Works in Progress programme, which involves works in early stages of their development that could benefit from community feedback to further develop ideas. The first work to pilot 


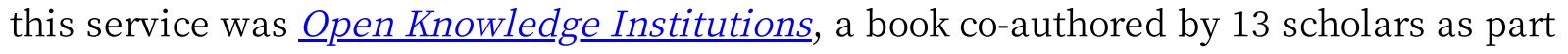
of a "Book Sprint," where the authors hosted the manuscript via Works in Progress. But the press has also released titles for formal assessment via their Community Review programme, which includes manuscripts of MIT Press contracted books, for example the manuscript for Data Feminisms, that are posted for public comment prior to entering the publication process. But beyond these open and community review experiments they also make a selection of previously published titles available via PubPub where the content is the same as the final published version available from the Press, including a COVID 19 collection, and a selection of books from Goldsmiths Press (․ㅡㄹearn, 2020).

\section{Open Peer Review}

The term "peer review" did not come into widespread use until the 1960s and 70s to describe processes of "refereeing", that originated in practices-based on an editorial system-developed by scholarly societies and communities of scholars to evaluate the intellectual merit of scholarly work. As Fyfe et al. outline, in the 60s and 70s the control of the measures of academic prestige (from the management of peer review to the development of metrics) was increasingly transferred from these communities of scholars or society publishers to commercial publishing organisations, who helped rebrand

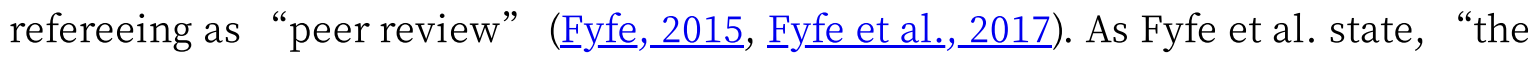
commercial publishers were able to colonise new sub-disciplines by adapting the societies' editorial processes: they recruited academics to act as editors, editorial board members and referees." This co-opted and rebranded "peer review" system turned into a vast industry and became a way for these publishers to legitimise their publications as venues for high-quality original research (.Fyfe, 2015), Fyfe et al. Godlee, 2000: 60).

This context is of particular interest if we look at the current changes again taking place and being proposed with respect to evaluation processes in a digital environment, as it makes clear, as Fyfe argues, that peer review is not inevitable and not the only possible marker of quality, but only "the currently dominant practice in a long and varied history of reviewing practices" (ㅌyeㄹ, 2015). The digital environment has made us question what authority is in an online setting, while at the same time offering potential opportunities to improve the evaluation and development of scholarship. This has led to various experiments with online and open peer review that focus on discussing the scholarship under review, which is what we will be focusing on in this section. We will support the argument that beyond evaluation and quality control, review practices within the humanities have been equally or more focused on constructive review and on community 
knowledge production, or on the "process of collaborative improvement of research" as Knöchelmann calls it, instead of being used predominantly as a gatekeeping practice (Knöchelmann, 2019). How can new forms of peer review further contribute to this coproduction of knowledge?

Ross-Hellauer and Derrick, similarly moving away from a focus on quality and gatekeeping, state that peer review is a "central pillar of self-governance in all scholarly communities" (Ross-Hellauer \& Derrick,2019). Yet they also acknowledge that it plays a central role in academic reward systems (from metrics to esteem and impact) as an audit and regulatory tool. They see the evolution of certain peer review practices in the humanities and social sciences derived from the sciences (e.g., its supposed role as a guarantor of facts and validity) as "a form of gradual colonisation of SSH by STEM values and notions of quality." By regulating what counts as quality or excellence in the humanities, this is altering how these disciplines can self-govern and are able to determine what counts as qualitative independent from STEM disciplines (Ross-Hellauer \& Derrick, 2019). Knöchelmann argues in this respect how it is important that the humanities at large should have their own discussions around the future of peer review and around opening up peer review in a digital environment, and not leave this to be adapted from the STEM fields-or even from for example the Digital Humanities alone (Knöchelmann, 2019).

Open peer review has been defined in various (sometimes contrasting) ways but in general it consists of a series of practices that aim to rethink how we conduct quality evaluation within scholarship, or otherwise filter research content. As Ross-Hellauer states "open peer review (OPR) is an umbrella term for a number of overlapping ways that peer review models can be adapted in line with the ethos of Open Science, including making reviewer and author identities open, publishing review reports and enabling greater participation in the peer review process" (․ㅡoss-Hellauer, 2017).. Not all of the practices they list under the banner of open peer review (such as open identities for example, or open review reports) necessarily stimulate online interaction with open texts. Open peer review does stimulate interaction when it takes place on the same online platform the publication has been published on, or when it involves review on a more granular paragraph or sentence level. In this sense in a public setting, open peer review has been one of the more common applications of open annotation in scholarly communication. Here, annotation takes the form of open and collaborative peer review whereby researchers are invited to critique a work published online (most commonly pre((formal) publication) using line-by-line commentary. 
In comparison to the sciences, where, often in combination with the practice of publishing preprints, open peer review has really taken off, in the humanities and in the context of book publishing we haven' t seen a similar development (yet). One notable and often mentioned example of open review by annotation is Kathleen Fitzpatrick' s Planned Obsolescence, a book published and reviewed online on the MediaCommons platform that allows line-by-line public annotation of texts (Fitzpatrick, 2011). $\underline{9}$ Fitzpatrick, as part of her experiments with open, community, or peer-to-peer review, has also formulated some strong critiques of the "traditional" or double-blind peer review model as it has been increasingly applied in the context of humanities book publishing too. For one, anonymous peer review, Fitzpatrick argues "effectively closes the author out of the main chronology of the conversation, which instead becomes a backchannel discussion between the reviewer and the editor" Fitzpatrick, 2011. The anonymity of authors and reviewers, implemented to prevent bias, is also seen by her and others as overrated in this system. As Fiona Godlee has argued, it doesn' t seem right that authors are assessed or judged via reviewers "hiding" behind anonymity, where anonymous review "has the effect of giving reviewers power without responsibility" Godlee, 2000. This "veil of anonymity" and the assessment of research by only a very select group of experts has contributed to what Ross-Hellauer calls "the black box nature of blind peer review," and its lack of transparency and accountability (Ross-Hellauer, 2017). Knöchelmann similarly talks about how double blind peer review is idealised as impartial and objective with respect to gender, nationality, institutional affiliation, or language (Knöchelmann, 2019). As many scholars have already indicated though, blind peer review does not protect against reviewer bias, as the system has not been very

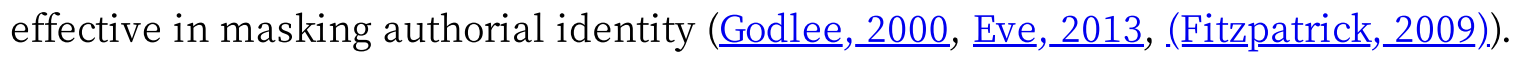

Fitzpatrick talks about alternative forms of "community-based authorisation" or crowdsourced review, that happen after publication instead of before. This opens review up beyond the opinions of a small selection of often senior scholars, which also runs the risk of being a system that breeds conservatism (e.g., towards emerging forms of knowledge). Open dialogue, as Rowe and Fitzpatrick argue "offers the possibility (...) of airing methodological or theoretical assumptions and biases rather than allowing them to remain covert points of contention within fields" (Fitzpatrick \& Rowe, 2010). In this context Martin Eve highlights the possible benefits of open peer review in the humanities for shedding light on what is often a secretive and opaque process where two or three reviewers have the ultimate say over whether a manuscript is published (Eve, 2014). It may reveal some of the biases and unfair assumptions that can take place within traditional, closed peer review, potentially working in favour of more equitable methods 
of assessment. $\underline{10}$ It comes down to "laying bare" the mechanisms of review, making this more transparent, Fitzpatrick argues (Fitzpatrick, 2012), and this includes being transparent over who the reviewers are. Their reputation might also add to the authority of the comments and with that the book under review.

An additional benefit is that readers and authors are placed in a conversation with each other, further, as Fitzpatrick calls it, "deepening the relationship between the text and its audience" (Fitzpatrick, 2012). In this sense for Fitzpatrick open peer review of long-form text can help build a community around a publication in a way that starts to elide the difference between author, reviewer, and reader. Open review necessitates a collegiate approach to review, being "helpful" rather than demonstrating how "smart" one is Fitzpatrick, 2011. By facilitating a conversation between author and reviewer in the open, editorial feedback can be a collaborative process rather than one necessarily grounded in antagonism or gatekeeping. In a similar vein, Nawrotzki et al. employed open peer review on their monograph Writing History in the Digital Age in order to "reexamine our established practices and realign them with our scholarly values” (Dougherty \& Nawrotzki,2013). Katherine Rowe talks in the context of open community review of "our crowd sourcing" where the crowd or public often remains a scholarly one, it isn' t "just anyone" commenting, there is a "preexisting community of practice" one is connecting to (․ㅡㄹ, 2010$)$. Yet it also opens publications up beyond communities of practices, and to people from outside of academia, which can further enrich the dialogue.

Finally, open peer review offers improved options for the evaluation of digital scholarship. For Roopika Risam, digital scholarship necessitates a reassessment of peer review practices, particularly because it differs from traditional single-author work. Digital scholarship is "often collaborative," "rarely finished," and "frequently public," meaning that new methods of assessment may be needed and appropriate (Risam, 2014). As Odell and Pollock state in relation to this, "blind pre-publication peer review does not work for a digital project that (by necessity) may be required to grow, evolve and change on the open web" (이 \& \& Pollock, 2016). Our common linear publishing and evaluation workflows therefore might need to be adapted. This would involve less assessment, validation, or gatekeeping, and more feedback to roll into the next phase of the digital project. Risam argues that these qualities are affordances rather than limitations of experimental digital scholarship, meaning that it should be "best understood as part of an ongoing trend in academic discourse prevalent enough to require rethinking of the production of academic value" (Risam, 2014). 
One of the main drawbacks of open peer review is the tension between anonymity and openness, where open peer review can lead to the introduction of bias (e.g., gender bias) and of self-censorship, where reviewers might blunt their critique and opinions in an open setting out of fear to cause offence. The anonymity in double-blind peer review can also serve as a means to further protect early-career or untenured reviewers and authors and can provide a protective function for them in an open forum. But on the other hand, as Rowe and Fitzpatrick also indicate "junior scholars are rarely part of a traditional reviewing process" and in this sense open peer review might offer them more exposure to and experience with the review process (Fitzpatrick \& Rowe, 2010). Nonetheless this power imbalance in open peer review needs to be taken into consideration and should be seen as a clear challenge within open peer review practices, how can we create an online space safe for interaction?

Another clear problem is creating a sufficiently large community around a scholarly book or publication, where scholars such as Skains have also indicated that this remains an issue in open review. This relates back to what we discussed in the previous section on open annotation, that there exists a general reticence to take part in open peer review having to do with the fact that (next to time-restraints) it is not sufficiently acknowledged in reward and evaluation systems. Yet at the same time the argument can be made that open peer review makes more visible the academic labour and service work that is actually done by reviewers to support their fields. In general however, a more substantial cultural switch might be needed, in which we start to focus more on seeing review as a contribution to collective knowledge production.

A challenge that also needs to be taken into consideration is the amount of editorial labour that comes into play with setting up open peer review systems and with moderating the process. From designing and implementing a new workflow, to bringing together a community to review, there is substantial labour involved in curating this process. As Rowe and Fitzpatrick state, “in this context, the editor' s role entails something more complex than what is required when processing two reader reports, since publication decisions may involve arbitrating between multiple competing reviews" (Fitzpatrick \& Rowe, 2010).

What is clear is that in order to develop new systems of review online and rethink peer review both for a digital environment and in the context of the humanities and academic book publishing, the maintenance of a community around publications or publication platforms, or the creation of scholarly communication and publishing networks, might be key to any future publishing system. Scholar-led presses might have an important and 
privileged role to play in this scenario as they are often deeply embedded already within certain research communities and fields. In addition to more communal forms of review, a move to forms of continual review, or review at different points of the research process, might also be needed (especially in the context of digital scholarship and experimental book publishing). This move might again also involve an investment in more formative forms of review. The Public Philosophy Journal already practices this type of peer review, which focuses, as they state on their website, on "transparency, community engagement, and ongoing, developmental conversations." Their review process involves supporting both the publications as they go through their development and the people involved in the formative peer review process. They do this by setting up "review teams" which

"develop an inclusive, supportive space in which ideas are explored and refined collaboratively". For them this practice of formative review and publishing is a way to create a publics and to support collegiality and academic service work. $\frac{11}{1}$ The focus here is shifted to producing knowledge as a community, which will prove essential to making this earlier mentioned cultural shift, where, as Fitzpatrick explains "for network-based publishing to succeed, the communal emphasis of network culture will have to take the lead over academic culture' s individualism" (Fitzpatrick, 2009).

One research and publishing project that deserves highlighting here as it looked at annotation and open peer review as a means to foster communication between scholars, is the HIRMEOS project (High Integration of Research Monographs in the European Open Science Infrastructure). As part of this project hypothes.is was implemented as an annotation service on the OpenEdition Books platform to conduct an open postpublication peer review experiment. The objective of this experiment was to create a space both for scientific conversation around publications and to stimulate new forms of peer review. The project has been really well-documented, among others via an extensive article and a project report (Bertino \& Staines, 2019, Dandieu \& HIRMEOS Consortium, 2019). The open peer review experiment included 13 open access books from four publishers and took place over several months. The publications selected for this experiment were monographs already published and peer-reviewed and the annotations were public and open to everyone to contribute. Publishers were involved directly to act as moderators (with the aid of a project assistant), write guidelines, and suggest reviewers. Some of the more interesting takeaways of this project include the importance of community outreach activities (involving both publishers and authors) and the formulation of clear guidelines, user guides, and rules of good conduct. Workload was one of the biggest inhibitions to take part for publishers, where similarly 'lack of time' was the main reason for reviewers. A reviewer community was created by both 
publishers and authors mainly through promoting the book on social media (e.g., Twitter, blogs). One issue potential reviewers seemed to be concerned about when they were initially approached was that authors might not be aware that their books were being annotated, which, as the report outlines, highlights the focus on interpersonal exchanges in these kinds of experiments. This direct exchange with the author was also exactly what reviewers appreciated most about their participation. Two further observations from the publishers' side include how publishers mentioned that their first priority was to include open access in their editorial policy and workflows, where the practice of open annotation was not seen as a priority and more as something maybe for a next phase. Secondly publishers questioned whether accommodating open peer review and annotation in this way went beyond the scope of their mission as publishers. The project report has formulated various recommendations, which we will come back to in part 3 of this report.

\section{Reuse and Remix}

In addition to annotation and open peer review, digital technologies afford the opportunity to reuse publications in a variety of ways through remix, reuse, and other post-publication experiments. Much of this is predicated on openly licensed research objects that enable reuse of scholarly publications. As Sarah Lippincott writes:

Digital publishing tools have emerged with a low barrier to entry and excellent user experience for both content creators and audience. These allow scholars to focus on making new forms of digital media-enhanced knowledge, rather than struggling with software. These tools work best when they exist on the open web - that is, when they can interoperate with other tools and systems, and when they facilitate reuse and remixing. Open texts facilitate creative use, reuse and engagement (Lippincott, 2016).

For Lippincott, the "low barrier to entry" that digital publishing affords, coupled with the open licensing of digital texts, has created a breeding ground for experimentation through reuse and remix of long-form works.

Reuse and remix are probably most well-known within a scholarly environment through their connection to open licenses, brought on by the increasing adoption of Creative Commons licenses that allow (commercial) reuse or derivatives within academic publishing. $\underline{12}$ In the context of the open access movement, reuse falls under the distinction introduced around 2006 by Peter Suber and Stevan Harnad between gratis and libre open access, $\underline{13}$ capturing a positive connotation (describing kinds of access rather 
than kinds of access barriers) in relation to the removal of price and permission barriers as formulated in the 2002 Budapest Open Access Initiative (part of the BBB definition of open access). But the focus on reuse rights ultimately derives from computer science and from the open software movement, where the original gratis/libre distinction concerns software-or code. $\underline{14}$

But reuse and remix can also be seen as lying at the basis of scholarly research and the academic writing process in general, where scholars build upon and extend the works and arguments of other scholars when they cite, reference, critique, analyse and reuse existing sources, and in this sense "derived use" can be seen as fundamental to the way in which scholarship builds on what has been published before and further progresses based on this. There are also specific reuse and remix practices that are already embedded in our publishing systems, such as the practice of including, republishing, or reworking previously published work in edited collections or into a monograph. And beyond that our publications themselves rework and incorporate different snippets of feedback from the various agencies involved in their production (from scholars to typesetters and designers). As Cullen and Bell argue in this context, "in its complex weaving and invocation of other works, the scholarly book is not only a fertile repository of ideas, knowledge, and research; it is also inherently social" (․ullen \& Bell, 2018).

Reuse and remix are practised in various ways in academia and are known under a variety of terms and concepts. Adaptation and appropriation are terms that are quite commonly used within an art and literature context, where they are mostly applied in a critical way to engage or critique issues of authorship, originality, intertextuality, ownership, and copyright. Within a legal context the terminology used most often is open licensing, which includes modifications, derivatives, fair use, or transformative use of texts, data, and resources, for example. And finally, within an open education context, the term Open Educational Resources (OER), indicating resources that are freely available for reuse by others, is most commonly used. Reuse and remix can include a variety of practices within humanities communication and publishing, including fairly common ones, such as republishing (as discussed earlier), translations, adapting books to new media (e.g., audiobooks), and the incorporation or mixing and sampling of different forms of media content (texts and images or videos for example); but they also include digital humanities derived methods of text and data mining, and data reuse (for example to create visualisations or image and media libraries or to adapt graphs, images, or diagrams). More experimental practices of remix and reuse include those in which open texts, images, or videos (e.g., vidding) are cut or mashed up or are re-interpreted as a form of critical engagement with the source texts, or are published with libre licenses to 
allow audiences to do so, or to explore and promote forms more equitable and collaborative forms of knowledge production.

Yet, as Martin Eve highlights, these practices are quite distinct or substantially differ from how reuse is perceived within computer science, and hence the argument for open licensing is different within the humanities-less about freedom of information and code, and more about the fact that existing copyright provisions (e.g., fair use) are not adequate to accommodate existing humanities research practices (Eve,2014). Yet beyond current copyright legislation not covering existing (collaborative and digital) research practices, many researchers also experiment with reuse and remix as a critical practice exactly to challenge existing liberal humanist copyright regimes and established ways of doing and publishing research and the connotations of individual authorship, originality, and the ownership of research that comes with them.

There are various reasons why open licensing might be beneficial for humanities research. For one, it can lead to a wider uptake of research, for example through translations of works. Vézina explains this as follows:

For instance, ND licenses prevent translations. Hence, given that English is the dominant language of academia, ND licenses place barriers to accessing knowledge by non-English speakers and limit the outreach of research beyond the Englishspeaking world. ND licenses also prevent the adaptation of the graphs, images or diagrams included in academic articles (unless separately licensed under a license permitting their adaptation), which are essential to achieve wider dissemination of the ideas expressed therein (Vézina, 2020).

Peter Suber (2012). provides a quite extensive list of the benefits of academic reuse, or of libre open access, many of which involve increased accessibility:

- to quote long excerpts

- to distribute full-text copies to students or colleagues

- to burn copies on CDs for bandwidth-poor parts of the world

- to distribute semantically-tagged or otherwise enhanced (i.e., modified) versions

- to migrate texts to new formats or media

- to keep them readable as technologies change

- to create and archive copies for long-term preservation

- to include works in a database or mashup

- to make an audio recording of a text

- to translate a text into another language 
- to copy a text for indexing, text-mining, or other kinds of processing

What is also important is that with open licensing reuse becomes possible without needing to request permission from the publisher or right owner. This permission seeking, as Martin Eve explains, exposes the power that publishers have to decide what gets published while at the same time putting researchers off from legitimate forms of reuse: "Such permission seeking puts copyright holders in a position to exercise veto power over the publication of research, especially research that deals with contemporary or popular media. These results demonstrate that scholars in communication frequently encounter confusion, fear, and frustration around the unlicensed use of copyrighted material. These problems, driven largely by misinformation and gatekeeper conservatism, inhibit researchers' ability both to conduct rigorous analyses and to develop creative methodologies for the digital age" (Eve, 2014). Similarly, with legislation differing worldwide, clear open licensing (for example in the form of Creative Commons licenses) supports the further uptake or reuse and remix practices in research.

Due to technological advancements, data-mining and associated technologies, such as visualisation and re-use of collections (e.g., large electronic text collections via methods

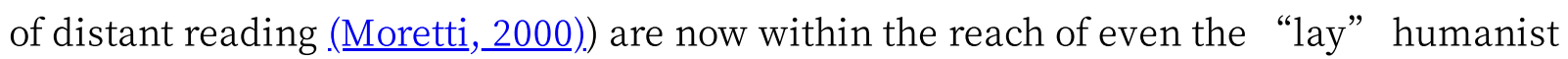
not well versed in computational methods. However, as Matthew Kirschenbaum points out, there "is a deep tradition of scepticism towards quantitative and empirical techniques among humanists, which too often smack of positivism and objectivity in domains for which interpretation, ambiguity, and argumentation are prized far above ground truth and definitive conclusions." (Kirschenbaum, 2007). Yet as Kirschenbaum makes clear, these methods are rooted in long-standing humanistic methods of reading and communication and are simply being further developed with the aid of the digital medium.

What is currently preventing the adoption of reuse, remix, and collaboration within the humanities is predominantly researcher inhibitions perpetuated by institutional structures and requirements. As Kathleen Fitzpatrick writes, academics are extremely conservative in their publishing practice and resistant to changing their ways of working, citing 'We Have Never Done It That Way Before' as a good motto for the academy more generally Fitzpatrick, 2011. One of the main critiques put forward by humanities scholars towards reuse and remix practices and open licensing is that they interfere with the academic integrity of their works, especially in cases where these practices concern perceived misuse of research (e.g., libel, plagiarism, false attribution, piracy). Yet as Vézina argues, copyright and open licensing in general are not the best frameworks to 
address issues of misuse of research, as this is mainly addressed through institutional and social norms and moral codes of conduct around plagiarism and misappropriation (Vézina, 2020). Neither traditional copyright, nor open licensing protect against research misuse, as Eve argues: "After all, works whose copyright has expired (therefore holding none of these protections and which the law explicitly permits anyone to use in any fashion) are still subject to these intra-academic norms. Conversely, others have sometimes built valuable, digital, scholarly projects around such works; enterprises that would be practically impossible without permission to modify the original” (Eve, 2014).

Others go even further in their critique of these practices, where it is not only misuse that they condemn. For example, the historian Peter Mandler outlines how any remixing or reusing of humanities texts is problematic where he stands by the unique originality of our words as researchers. As he explains, "our form of words is unique to us and it cannot be dismembered and mixed with the words of others." This he states would lead to plagiarism as it doesn' t allow us to distinguish anymore (through quotations) which words are owned by whom. Related to this is the strong normative assumptions of the proprietary nature of scholarship, or the idea that (the level of) reuse should be determined by the individual author of a publication. Many of these objections to reuse arise in the literature around Creative Commons licenses, particularly CC BY, that provide blanket permission to reuse scholarship (if attribution is provided). Mandler describes this as the "booby-traps" for humanities scholars that are embedded with the CC BY licence, particularly the ability of a scholar to remix content in ways of which the original author does not approve:

Often it is very difficult to work out how the work has been changed, and meanwhile the new work acquires authority not only from the name but from the words of the original author. There are lots of reasons why humanities scholars - and indeed many scientists, who when given a choice most often prefer a 'non-derivative' licence over CC BY - have promoted other CC licences that facilitate open access but not this kind of reuse. For one thing, we do not have full ownership of our texts ourselves - we use others' words and images, often by permission (Mandler, 2014).

Mandler posits an association with CC BY, reuse, and a lack of control over what happens to their work once it has been reused, where remixing and reusing scholarship for him undermines the authority of the original author. Such scepticism of the CC BY licence is common within the humanities, particularly in response to policy consultations that mandate CC BY as the default licence for open access (Kingsley,_2016, The British Academy, 2018, Arts and Humanities Alliance, 2019). 
Gary Hall interrogates the scepticism with CC BY from an alternative perspective that it affords too much control to the original author by requiring attribution and thus associating the work as property of the author. This works against reuse by preventing the creation of a "common stock" of digital materials to be used and reused by whomever wants to do so. Instead, CC BY presumes that the digital material is the author' $s$ "property" and so offers merely a reformist take on intellectual property instead of a

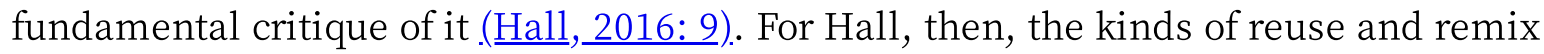
encouraged (but not completely supported) by CC BY would thus depend on the

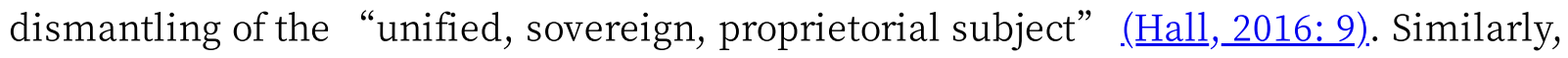
Janneke Adema writes "although remix practices in academia (...) have the potential to shake up the authorship function, until now they have not managed to dethrone the traditional academic author-god-and in some cases, they even reinforce her or him" (Adema, 2021).

In practice though, many humanities scholars find potential remix of their books problematic as it interferes with their propriety and sense of ownership of their texts. This is not surprising given how authorship functions within academia, where as we outlined previously, single authored, original thoughts and publications are preferred, and remix, reuse, and other more collaborative forms of research (e.g., creating databases) are not as readily acknowledged as scholarly research, meaning there is little incentive for scholars to (further) experiment with these forms and practices.

Another complication with reuse is in cases where it concerns the reuse of indigenous or community knowledge, for example in anthropological settings, where "questions of ownership, control, access, and possession (OCAP) of intellectual property and cultural materials are key considerations for Indigenous communities, who since the time of contact with settler populations have seen their cultural content stolen, misappropriated, and misrepresented" (Cullen \& Bell, 2018). In addition to this traditional and indigenous knowledge often has its own cultural and access protocols, determining if and how that knowledge can be (re)used and circulated, by whom, and under which conditions, which also further complicates common open-closed binaries (Christen, 2012). As Bell and Cullen point out, the publishing process, with its focus on copyright, single authorship, and the bound book (which implies knowledge is not always easily available for further remix by the community) often doesn' t accommodate collaboration with diverse knowledge communities. As they explain, "authors and local communities often note, however, that fruitful collaborations often end once a manuscript is 'in press.' At that point, the academic author assumes full responsibility for seeing the book through the editorial and production processes to publication. And when authors and publishers do 
attempt to do justice to the rich content at their disposal (audio files, film, images of cultural artefacts), they run up against a publication process that reinstates old authorial hierarchies and the limitations of the printed book" (Cullen \& Bell, 2018). Indigenous and traditional knowledge is often audio-visual, which modern digital recording, transmission, and preservation technologies lend themselves well to. In this sense, as they state: "In these fields, there is a pressing need for a different kind of publishing, both for collaborative authorship and for more flexible, interactive publications" (Cullen \& Bell, 2018). What is important in this context, as Okune et al. have outlined, is that clear research contracts with indigenous communities are set-up and co-designed with the communities "to define when, where and how their community knowledge is used by external researchers" (․kune, Hillyer, Chan, Albornoz, \& Posada, 2019).

Cullen and Bell explain how the books they are publishing at UBC Press, which draw upon indigenous resources or databases, can, through open licensing (in their case through the use of Traditional Knowledge Licenses) be accessed, shared, and repurposed while respecting cultural protocols and different understandings of OCAP. For them, even though the books and the collections they draw upon remain separate, it proved essential to link the books back to the project or materials they were researching, to ensure the books themselves again become part of the indigenous commons: "It was critical to the research teams, however, that the books remain a part of the project' s full suite of outcomes and resources" (․ullen \& Bell, 2018). The reuse of resources included in books also remains an issue within other settings in relation to third-party rights, for example in the case of images, and/or musical, or choreographical scores included within books. In many arts and humanities disciplines the rights to research materials are owned by others who need to provide permission for their reproduction. This has made it more difficult to attach open licenses to books as a whole.

Due to these (often perceived) legal and moral difficulties around reuse and remix in the humanities and for books in particular, within the open access movement libre access has often (as a matter of strategy) been de-prioritised in order to focus first and foremost on making the majority of the research accessible online without a paywall (gratis open access) (Adema \& Hall, 2013). Once this is achieved, activists such as Stevan Harnad have argued, libre forms of open access can be explored (Harnad,2012). Yet many others fear that this strategy has led to a reduced uptake of reuse and remix within the humanities and further strengthens the general tension within open access between access and openness (Moore, 2017). A further complication might be that the libre open access strategy has in most settings combined commercial reuse with the right to derivatives and modifications (i.e. a focus on the CC BY license), where for example in the context of 
much publishing in Latin-America-where, different national and regional contexts notwithstanding, the focus is predominantly on non-commercial scholarship and publishing-there is a distrust of CC BY’ $s$ focus on commercial reuse (Lujano, 2017).

Other literature on inhibitions towards reuse and collaboration focus on more technical considerations around software design and implementation. Writing about University of Minnesota's Manifold software, Kasprzak and Smyre highlight how experimental practices need to be embedded within a publishing workflow from the outset. As reuse tends to occur after a work has been published, workflows for iterative publishing need to adopt a more holistic approach to experimental publishing that recognises different starting points within each publishing process (the "end point" of one publication may be the beginning of another). Publishers need to therefore get involved with the editorial workflow in order to "feel comfortable" with the ideas from the early stages (Kasprzak \& Smyre, 2017: 97). Ball and Eyman explore similar issues from the perspective of the editorial workflow, or the lack of "any editorial management systems available to support this kind of publishing" . Editorial management system design requires consideration of a host of new practices of open review, citation, version control and collaborative review of what they term "webtexts" (Ball \& Eyman, 2015).

One often-cited example of reuse and remix is the Living Books About Life book series published by Open Humanities Press and edited by Clare Birchall, Gary Hall, and Joanna Zylinska. This series "repackaged" previously published open access content into curated edited collections on particular themes. The books in this series are "living" in the sense that they are "open to ongoing collaborative processes of writing, editing, updating, remixing and commenting by readers" (Birchall, Hall, and Zylinska n.d.). In doing this, the researchers showed the ability of reuse to deconstruct some of our preconceptions of what a book actually is, leading Gary Hall to pose the question: "What

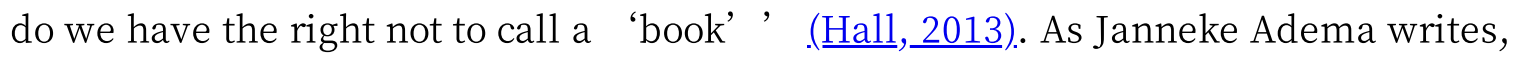
Living Books About Life displays a "continued theoretical reflection on issues of fixity, authorship and authority, both by its editors and by its contributors in various spaces connected to the project" (Adema, 2015). Some observations from the original project included the lack of familiarity of the editors of the collection with open licensing and which publications they were allowed to reuse, next to a lack of actual remixing taking place on the level of the wiki-books (which might have partly to do with how they were still presented as "books" with clear authors and cover pages on the platform). However, on the level of conceptual experimentation with the aim of stimulating conversations around what a scholarly book is and can be (amongst others on the project

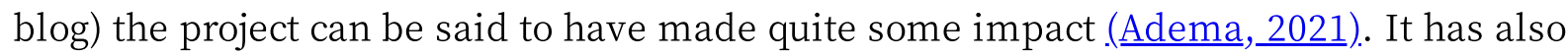


stimulated experimentation with living books by other publishers and author communities, including at least three further adaptations of the model, namely $\underline{\text { The }}$ Living Bibliography of Animal Studies, Living Books about History, and En busca del quelite perdido.

Within the COPIM project we have been experimenting with still other practices of remix and reuse, including as part of one of our Pilot Projects, Combinatorial Books: Gathering. Flowers, which explores and encourages the revisiting and rewriting of books within the Open Humanities Press catalogue as a means of generating radical new responses to them. This Pilot Project wants to create a research and publishing workflow that enables the creation of new combinatorial books out of existing open access books (or collections of books) that are available for reuse. For its first iteration, a group of Mexican scholars and technologists is rewriting and "re-composing" The Chernobyl Herbarium: Fragments of an Exploded Consciousness by philosopher Michael Marder and artist Anaïs Tondeur "through disappropriation as much as appropriation" ( following Cristina Rivera Garza), where the re-writing team is envisioning re-writing as an "exposing the incomplete, processual nature of any text; it is about making time and taking the time, and it is about relating to others in accountable ways" (Adema, Hall, \& Cota, 2021).

\section{Open and Social Scholarship}

The opening up of scholarship (beyond gratis and libre openness) includes making sure that books and publications are connected or networked more directly and that conversations around scholarship can arise. For many scholars “openness" does not mean a lot if there is no actual engagement around a work or if no further connections are being made with related scholarship. Open access, or making books openly available, is in this respect not an end in itself in a scholarly communication context, where openness might also have to include "active collaboration, community building, and knowledge mobilization" (A Arbuckle, Meneses, \& Siemens, 2019). Scholarly conversations are partly reflected in our referencing systems, but digital tools and networked environments open up the possibility for our books to be engaged with more extensively and directly. However, this engagement can be hampered by the sheer volume of work being published and the lack of time available to scholars to interact with it in a meaningful way, which means filtering for relevance has become an essential knowledge management strategy (for example by publishing in certain venues). But beyond preventing "filter failure", authors and publishers might also want to think about presenting open scholarship in such a way that others want to engage with it. As Alyssa Arbuckle argues: "straightforward access does not suffice for all readers-how can we 
present research in ways that our colleagues across disciplines and institutions, as well as other members of the general public, can find, understand, and use?" (․ㅏbuckle, 2019). How can we facilitate "social knowledge creation, public engagement, and broad collaboration" in a move that Arbuckle and her colleagues from the INKE partnership have formulated as a move from open access to open, social scholarship, or scholarship that is more socially engaged?

Social media has been very influential in this context, as has the increasing networked state of our knowledge, which has enabled us to create communities around our scholarship, and likewise open and digital books have played an active role in the creation of communities (Fitzpatrick, 2011; Hyde, 2016; McHardy,_2021). As Maxwell argues in this respect "publication is not making things available to a pre-existing public; it is the very constitution or gathering of that public" (Maxwell,2015). Creating these relationalities around books to be able to connect with others also partly determines their relevance, where, as Maxwell argues, relevance is not only defined by our publication venues, but it is much more dynamic and is defined in an ongoing way by the engagement of readers. In this sense, as he argues, we can increase the relevance of our publications by "making it more easily linkable, shareable, portable, commentable, convertible, and transformable" (Maxwell, 2015). McGregor and Guthrie are similarly interested in exploring how beyond offering free access to our publications, we can enable more "productive use" of our research (which relies on several factors, from promoting literacy and awareness, to access to technology), where Maxwell focuses on how we can enable more "transformational uses by scholars and other readers" (McGregor \& Guthrie, 2015; (Maxwell, 2015)).

Within the humanities and social sciences, most marketing, dissemination, and discovery has traditionally been done by publishers. But increasingly scholars themselves through their networks and via social media, and through their establishment as "academic brands" or "entrepreneurs of themselves" within the scholarly

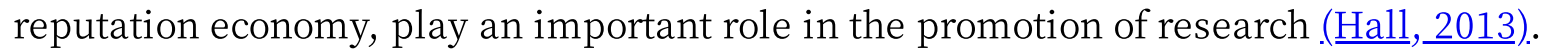
Digital tools and networked environments make it easier to create communities around books, where a project or platform such as for example CommentPress, was set up to channel the social and participatory strengths of the blog format into a (book) publication platform. Fitzpatrick asked specifically whether we could refashion the blog form to "enable social interaction around long-form texts" (Fitzpatrick, 2007). The digital text in this sense is very well suited to, as Fitzpatrick states "produces the greatest possible readerly and writerly engagement, that enables both the intensive development of an idea within the bounds of the electronic text and the extensive situation of that idea 
within a network of other such ideas and texts" (Fitzpatrick, 2007). Hypertext, as a networked data structure, has been crucial in creating this interaction, for example by delinearising text, and by promoting readerly interaction and interconnections between texts via hyperlinks. Hypertext, as Fitzpatrick argues was thus seen as "a means of creating a new, more active relationship between the reader and the text" , where CommentPress was set up to fulfill this need of situating long-form text "within a social network, within the community of readers who wish to interact with that text, and with one another through and around that text" (․ Fitzpatrick, 2007). In a way what we want to recreate with our social and networked text, she argues, is the digital equivalent of a "coffeehouse" or even of a scholarly conference.

But next to engagements around or connected to books and their publication platformsas exemplified in CommentPress or platforms such as PubPub or via practices such as open annotation and open peer review-social interactions and conversations around research also take place elsewhere (and maybe increasingly so), on different communication platforms. Similar to how we discuss research at physical or online conferences, conversations are taking place on social media or on dedicated and often proprietary platforms, making connections to the publications being discussed via hyperlinking and tags. Next to "academic" Twitter and Facebook these conversations are also taking place on Social Research Sharing Networks (SRSNs) such as Academia.edu, ResearchGate, and Humanities Commons. Although academics use of social media goes well beyond conversations or discussions around specific pieces of scholarship, there is of course a clear opportunity here for scholars and publishers to both explore how they can harness these platforms more to increase engagement around scholarship and how they can make links back to the scholarship under discussion to ensure these conversations are collected, findable, and archived. At the same time it is a matter of concern how these "external conversations" for a large part take place on commercial networks or platforms, some of which (such as for example academia.edu) are directly invested in creating profits based on scholarly interactions on these platforms (and often ask scholars to pay to access their interactive features as part of their business models). (Adema \& Hall, ongoing). Making these kinds of conversations that take place elsewhere visible and findable is also increasingly being explored by alternative evaluation systems such as altmetrics that collect and collate these disparate online conversations, but in the form of a metric that says little about the actual conversations taking place or the relationalities between publications that are being woven. As Maxwell argues in this respect, how can we "re-inscribe the relation between works, publications, and discourse more broadly" (Maxwell, 2015). Fitzpatrick makes clear here that "the issue of engagement, moreover, 
is not simply about locating the text within the technological network, but also, and primarily, about locating it within the social network" and from there "making those conversations as accessible and inviting as possible should be the goal in imagining the textual communications circuit of the future" (Fitzpatrick, 2007).

One clear example of long-form scholarship that has made use of the affordances of social scholarship and social media are hashtag syllabi (\#Syllabus), which are found on the Internet and are "often compiled by people inside and outside of the academe, including activists and scholars and are often People of Color, women, and other minoritized peoples" (Lyons, 2019; Graziano, Mars, \& Medak, 2019). Other examples include crowdsourced projects (often drawing on citizen science and citizen scholarship principles) such as Transcribe Bentham, where the public was asked to assist with transcribing the manuscripts of the English philosopher Jeremy Bentham, which were subsequently used in the production of the edition of The Collected Works of Jeremy Bentham. A great resource to explore additional works of open social scholarship is the $\underline{\text { Open Social }}$ Scholarship Annotated Bibliography, where the bibliography is itself an example of open social scholarship too, as "the authors of the 'Open Social Scholarship Annotated Bibliography' enacted social knowledge creation practices in the assemblage of this bibliography by collaboratively setting the intellectual direction of the work, compiling resources, and annotating them” (El Khatib et al.,2019).

\section{Emergent Practices: Versioning, Forking, and Computational Interactions}

Various forms of interaction and engagement around texts and publications are experimented with within a STEM or Digital Humanities environment initially, from where they then become more widely applied and used in general humanities and social sciences contexts too. This is the case with several of the practices described above, for example (open peer review, open annotation etc.)-although the humanities itself also has an established track record of being at the vanguard of experimenting with hypertext, networked books, and new emergent genres. This final section describes various interactive practices that are increasingly used in STEM and DH but that are making their way into wider scholarly contexts too. One of these is versioning, also known as processual, iterative, or continuous publishing, which is a practice that within STEM fields has been initially pioneered with the use of preprints and postprints, for example. Adema (2021). argues that as "a concept and practice, versioning, as it has come to be used within academic research and publishing, refers to the frequent updating, rewriting, or modification of academic material that has been published in a formal or informal 
way. As a practice, it has affinity with software development, in which it is used to distinguish the various installments of a piece of software." However, she explains that versioning and revision has a rich tradition within the humanities too (see disciplines such as textual criticism, for example). Increasingly open publishing platforms that focus on humanities and social sciences fields have started to formally incorporate versioning and options to update and revise works. PubPub and the Manifold Scholarship publishing program are two key examples here, which allow material (text, data, sound, video) to be added to a publication as it progresses or is iteratively published. With the possibility to keep changelogs and previous versions available, the modifications, interactions, comments, annotations, and updates to publications can become more visible, which offers possibilities to highlight the co-creation of and engagement with scholarship. Various experiments with versioning in the humanities and social sciences have previously taken place, including Lawrence Lessig's Code 2.0 and Mckenzie Wark's Gamer Theory, for example.

Another form of interaction not dissimilar from versioning is the practice of forking, similarly derived from software development. Forking refers to the creation of a derivative version of a previously published text or publication to make revisions to it or customise it to a different context. Syllabi are for example sometimes 'forked' to be adapted to specific courses or educational environments. Where versioning often happens by the same (group of) authors of the original text, forking tends to involve different author communities, and can be seen as a more direct reuse of existing research in this sense. But forking books is also being proposed as a potential future for publishing by scholars such as Sarah Ciston and Mark Marino, who describe their experiment in forking Soon and Cox' s book Aesthetic Programming as "participating in the development of their book and the evolution of the codex book itself from a static product into an ongoing, iterative, process" (Marino \& Ciston, 2021). As they describe it their fork both reuses and extends the existing book and as to the conversation, as they state "following the "yesand' ethos of its collaborating first authors." Previously developed forking and collaborative scholarship projects include Workbench (now obsolete), a fork of the publishing platform Scalar, designed by Jessica Pressman, Mark C Marino, and Jeremy Douglass in collaboration with Lucas Miller, Craig Dietrich, and Erik Loyer. Workbench promoted scholarly collaboration by allowing scholars to "create, join, or clone online arguments enhanced with multimedia content" where "the clone feature allows scholars to copy entire books so they can build their own interpretations" (Marino, 2015). Beyond versioning and forking, still based on human iterations and adaptations, interaction with texts increasingly also happens in automated ways (e.g., through 
automated discovery) or through computational interactions. $\underline{15}$ Computational interactions are increasingly important to establish semantic links in plain texts, but what is needed to support this is that texts are machine readable, which will allow semantic discovery and the linking of online texts and data (for example indexes and references in scholarly books) as well as further text and data mining and distant reading applications (Kirschenbaum, 2007). Yet beyond the lack of openly available books in the humanities, the prevalence of the static PDF format in open publishing has been much derided within DH circles and by scholars experimenting with networked books and semantic linking (Walkowski, 2019). Notable projects that have explored linking and networking (collections of) books (or data within and connected to books) include the Enhanced Networked Monographs (ENM) project, an experimental publishing project funded by The Andrew W. Mellon Foundation, which provided an integrated index based on back-of-book indexes of a corpus of 110 back-list scholarly monographs from various (mainly humanities) disciplines by extracting topics from indexes, which were subsequently curated and presented on a platform for reading (․ㅏrovo, 2019).

But beyond the need to situate texts and books into technological networks, there is still the need to situate them, as the Fitzpatrick quote mentioned earlier, within a social network too, "within the community of readers who wish to interact with that text, and with one another through and around that text." Similarly, Christie (2014) argues that interactivity is "not (uniquely) a function of interface, but rather one of interpretation and argument." In this respect, Christie argues, it is the combination of interactivity as both an aspect of scholarship and a design principle, that will help us make strategic infrastructural investments to ensure attention and engagement are optimally cultivated. The next section of this report will discuss some of the ways, tools, technologies and platforms can stimulate this kind of engagement, while discussing and showcasing examples of publishing projects, best practices, and guidelines to support this.

\section{References}

4.1: Annotating a Text. (2020, May 6). Humanities LibreTexts.

https://human.libretexts.org/Bookshelves/Languages/English_as_a_Foreign_Language/Boo k\%3A_Advanced_Community_College_ESL_Composition_-

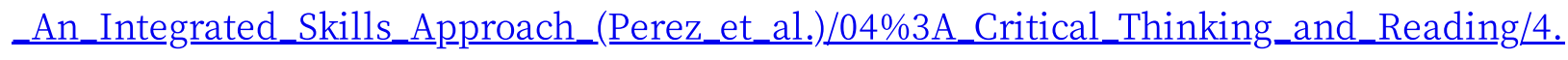
01\%3A_Annotating_a_Text 
Adema, J. (2015). Knowledge Production Beyond The Book? Performing the Scholarly Monograph in Contemporary Digital Culture [Coventry University].

http://curve.coventry.ac.uk/open/items/8222ccb2-f6b0-4e5f-90de-f4c62c77ac86/1/

Adema, J. (2018). Performative Publication (T\&F published version). Journal of Media Practice and Education, 19(1), 68-81. https://doi.org/10.1080/14682753.2017.1362174

Adema, J. (2021). Living Books: Experiments in the Posthumanities. MIT Press.

Adema, J., \& Hall, G. (n.d.). Liquidbooks / The Academia_edu Files. Retrieved 20 October 2021, from

http://liquidbooks.pbworks.com/w/page/106236504/The\%20Academia_edu\%20Files

Adema, J., Hall, G., \& Cota, G. M. (2021). Combinatorial Books-Gathering Flowers-Part I. COPIM. https://doi.org/10.21428/785a6451.d3ecc6cc

Adema, J., \& Stone, G. (2017). Changing publishing ecologies: A landscape study of new university presses and academic-led publishing (p. 102). Jisc.

http://doi.org/10.5281/zenodo.4420993

Ahearn, C. (2020). Pathways to PubPub. MIT Press Open.

https://mitpressonpubpub.mitpress.mit.edu/pub/pathways/release/1

Angell, N. (n.d.). AnnotatED Bibliography. Hypothesis. Retrieved 30 November 2020, from https://web.hypothes.is/education/annotated/bibliography/

Annotations on OpenEdition Books. (n.d.). Retrieved 21 November 2020, from https://www.openedition.org/22530

Arbuckle, A. (2019). Open+: Versioning Open Social Scholarship. KULA: Knowledge Creation, Dissemination, and Preservation Studies, 3, 18-18.

https://doi.org/10.5334/kula.39

Arbuckle, A., Meneses, L., \& Siemens, R. (2019). Introduction, Beyond Open: Implementing Social Scholarship. KULA: Knowledge Creation, Dissemination, and Preservation Studies, 3, 8-8. https://doi.org/10.5334/kula.55

Arts and Humanities Allianc. (2019, January). Plan S Consultation response from the Arts and Humanities Alliance. http://artsandhums.org/news-2/plan-s-consultation-response/

Ball, C. E., \& Eyman, D. (2015). Editorial Workflows for Multimedia-Rich Scholarship. Journal of Electronic Publishing, 18(4). https://doi.org/10.3998/3336451.0018.406 
Bauer, M., \& Zirker, A. (2015). Whipping Boys Explained: Literary Annotation and Digital Humanities. Literary Studies in the Digital Age.

https://dlsanthology.mla.hcommons.org/whipping-boys-explained-literary-annotationand-digital-humanities/

Bertino, A. C., \& Staines, H. (2019). Enabling A Conversation Across Scholarly

Monographs through Open Annotation. Publications, 7(2), 41.

https://doi.org/10.3390/publications7020041

Borgman, C. (2007). Scholarship in the digital age: Information, infrastructure, and the Internet. MIT Press.

Brown, M., \& Croft, B. (2020). Social Annotation and an Inclusive Praxis for Open Pedagogy in the College Classroom. Journal of Interactive Media in Education, 2020(1), 8. https://doi.org/10.5334/jime.561

Chan, L., Okune, A., Hillyer, B., Albornoz, D., \& Posada, A. (Eds.). (2019). Contextualizing Openness: Situating Open Science (Illustrated edition). University of Ottawa Press and the International Development Research Centre.

Chen, B. (2020, May 11). Using Web Annotation for Web Annotation Research. Bodong Chen. https://meefen.github.io/post/2020-05-11-web-annotation/

Chenoweth, K. (2018, April 16). Derrida’ s Margins [Text]. Derrida's Margins. https://derridas-margins.princeton.edu/

Christen, K. A. (2012). Does Information Really Want to be Free? Indigenous Knowledge Systems and the Question of Openness. International Journal of Communication, 6(0), 24.

Christie, A. (2014). Interdisciplinary, Interactive, and Online: Building open communication through multimodal scholarly articles and monographs. Scholarly and Research Communication, 5(4). https://doi.org/10.22230/src.2014v5n4a190

Ciston, S., \& Marino, M. C. (2021, August 19). How to Fork a Book: The Radical Transformation of Publishing. Medium. https://markcmarino.medium.com/how-to-fork-abook-the-radical-transformation-of-publishing-3e1f4a39a66c

Cohen, P. (2010, August 23). Scholars Test Web Alternative to Peer Review. The New York Times. https://www.nytimes.com/2010/08/24/arts/24peer.html 
Critchlow, T. (n.d.). Annotations. Retrieved 1 December 2020, from http://tomcritchlow.com/blogchains/annotations/

Crossick, G. (2016). Monographs and Open Access. Insights, 29(1), 14-19.

https://doi.org/10.1629/uksg.280

Cullen, D., \& Bell, A. (2018). The Social Text and Networked Knowledge: New Modes of Scholarly Book Publishing in Indigenous Studies. Journal of Scholarly Publishing, 49(2), 193-212. https://doi.org/10.3138/jsp.49.2.193

Dandieu, C., \& HIRMEOS Consortium. (2019). Report on Post-Publication Open Peer Review Experiment. https://doi.org/10.5281/zenodo.3275651

Dougherty, J., \& Nawrotzki, K. (Eds.). (2013). Writing History in the Digital Age. University of Michigan Press. https://doi.org/10.2307/j.ctv65sx57

Drucker, J. (2013). The Virtual Codex from Page Space to E-Space. In A Companion to Digital Literary Studies (pp. 216-232). John Wiley \& Sons, Ltd.

https://doi.org/10.1002/9781405177504.ch11

Dyson, E. (2017, May 12). Keynote. I Annotate 2017. https://www.youtube.com/watch? $\underline{\mathrm{v}=\mathrm{T} \_\mathrm{mTCFFrQ}} \underline{4 \mathrm{~A}}$

El Khatib, R., Seatter, L., Hajj, T. E., Leibel, C., Arbuckle, A., Siemens, R., Winter, C., \& Groups, the E. and I. R. (2019). Open Social Scholarship Annotated Bibliography. KULA: Knowledge Creation, Dissemination, and Preservation Studies, 3, 24-24. https://doi.org/10.5334/kula.58

Eve, M. P. (2013, March 15). The Future of Peer Review. Martin Paul Eve. https://eve.gd/2013/03/15/the-future-of-peer-review/

Eve, M. P. (2014). Open Access and the Humanities. Cambridge University Press.

Faulkes, Z. (2014). The Vacuum Shouts Back: Postpublication Peer Review on Social Media. Neuron, 82(2), 258-260. https://doi.org/10.1016/j.neuron.2014.03.032

Fitzpatrick, K. (2007). CommentPress: New (Social) Structures for New (Networked) Texts. https://doi.org/10.3998/3336451.0010.305

Fitzpatrick, K. (2009). Peer-to-Peer Review and the Future of Scholarly Authority. Cinema Journal, 48(2), 124-129. https://doi.org/10.1353/cj.0.0095 
Fitzpatrick, K. (2012). Beyond Metrics: Community Authorization and Open Peer Review. In Debates in the Digital Humanities. University of Minnesota Press. https://doi.org/10.5749/minnesota/9780816677948.003.0046 online at https://dhdebates.gc.cuny.edu/read/untitled-88c11800-9446-469b-a3be3fdb36bfbd1e/section/85c853b3-1660-4bdf-b3e2-69ade8bf3c7b\#ch26

Fitzpatrick, K., \& Rowe, K. (2010). Keywords for Open Review. LOGOS: The. Journal of the World Book Community, 21(3-4), 133-141.

Fyfe, A. (2015, June 25). Peer review: Not as old as you might think. Times Higher Education (THE). https://www.timeshighereducation.com/features/peer-review-not-oldyou-might-think

Fyfe, A., Coate, K., Curry, S., Lawson, S., Moxham, N., \& Røstvik, C. M. (2017). Untangling Academic Publishing: A history of the relationship between commercial interests, academic prestige and the circulation of research. Zenodo. https://doi.org/10.5281/zenodo.546100

Gius, E., \& Jacke, J. (2017). The Hermeneutic Profit of Annotation: On Preventing and Fostering Disagreement in Literary Analysis. International Journal of Humanities and Arts Computing, 11(2), 233-254. https://doi.org/10.3366/ijhac.2017.0194

Godlee, F. (2000). The Ethics of Peer Review. In A. H. Jones \& F. McLellan (Eds.), Ethical Issues in Biomedical Publication. Johns Hopkins University Press. http://ebookcentral.proquest.com/lib/coventry/detail.action?docID=3318111

Graziano, V., Mars, M., \& Medak, T. (2019). Learning from \#Syllabus. Humanities Commons. https://doi.org/10.17613/NKTX-KA69

Grove, J. (2020, March 20). Licence to 'remix' research alarms humanities scholars. Times Higher Education (THE). https://www.timeshighereducation.com/news/licenceremix-research-alarms-humanities-scholars

Gunn, L. (2016, May 24). Involving Page Owners in Annotation. Hypothesis. https://web.hypothes.is/blog/involving-page-owners-in-annotation/

Hall, G. (2013a). \#Mysubjectivation. New Formations: A Journal of Culture/Theory/Politics, 79(79), 83-102. https://doi.org/10.3898/NEWF.79.05.2013

Hall, G. (2013b). The Unbound Book: Academic Publishing in the Age of the Infinite Archive. Journal of Visual Culture, 12(3), 490-507. 
https://doi.org/10.1177/1470412913502032

Hall, G. (2016). Pirate Philosophy: For a Digital Posthumanities. MIT Press.

Harnad, S. (2012, May 3). Open Access: Gratis and Libre. Open Access Archivangelism. http://openaccess.eprints.org/index.php?/archives/885-Open-Access-Gratis-and-Libre.html

Hilton III, J., Wiley, D., Stein, J., \& Johnson, A. (2010). The four 'R' s of openness and ALMS analysis: Frameworks for open educational resources. Open Learning: The Journal of Open, Distance and e-Learning, 25(1), 37-44. https://doi.org/10.1080/02680510903482132

HIRMEOS Consortium. (2019). Annotation Service for Digital Monographs. https://web.archive.org/web/20201230170353/https://www.hirmeos.eu/wpcontent/uploads/2019/06/HIRMEOS_Annotation_-Fact_sheet-Final-version.pdf

Humphreys, A., Spencer, C., Brown, L., Loy, M., \& Snyder, R. (2018a). Reimagining the Digital Monograph: Design Thinking to Build New Tools for Researchers. The Journal of Electronic Publishing, 21(1). https://doi.org/10.3998/3336451.0021.102

Humphreys, A., Spencer, C., Brown, L., Loy, M., \& Snyder, R. (2018b). Reimagining the Digital Monograph: Design Thinking to Build New Tools for Researchers. The Journal of Electronic Publishing, 21(1). https://doi.org/10.3998/3336451.0021.102

Hyde, A. (2016, November 30). Facilitators not Editors, Collaborators not Writers. Adam Hyde. https://www.adamhyde.net/facilitators-not-editors-collaborators-not-writers/

Hypothes.is. (2019). User guide: Finding your way. La Maison Des Revues. Site d' information et d' accompagnement Éditorial. http://www.maisondesrevues.org/1281

Hyvönen, E. (2020). Using the Semantic Web in digital humanities: Shift from data publishing to data-analysis and serendipitous knowledge discovery. Semantic Web, 11(1), 187-193. https://doi.org/10.3233/SW-190386

Ide, N., \& Pustejovsky, J. (Eds.). (2017). Handbook of Linguistic Annotation. Springer Netherlands. https://doi.org/10.1007/978-94-024-0881-2

Jankowski, N. W., Scharnhorst, A., Tatum, C., \& Tatum, Z. (2012). Enhancing Scholarly Publications: Developing Hybrid Monographs in the Humanities and Social Sciences (SSRN Scholarly Paper ID 1982380). Social Science Research Network. https://doi.org/10.2139/ssrn.1982380 
John Maxwell, Leena Desai, Carmen Tiampo, Kim O’ Donnell, Avvai Ketheeswaran, Melody Sun, Emma Walter, \& Ellen Michelle. (2019). Mind the Gap: A Landscape Analysis of Open Source Publishing Tools and Platforms (1st ed.). Canadian Institute for Studies in Publishing, Simon Fraser University. https://mindthegap.pubpub.org/DOI: $\underline{10.21428 / 6 b c 8 b 38 c .2 e 2 f 6 c 3 f}$

Johnson, G. J. (2017). Through struggle and indifference: The UK academy's engagement with the open intellectual commons [Doctoral, Nottingham Trent University]. http://irep.ntu.ac.uk/id/eprint/31531/

Joy, E. A. (2018). 'An Instrument for Adoration’ :A Mini-Manifesto Against Metrics for the Humanities (To Be Elaborated Upon at a Further Date). In meson press (Ed.), Humane Metrics/Metrics Noir. Post Office Press, Rope Press, and meson press.

https://hcommons.org/deposits/item/hc:19823/

Kalir, J. H. (2019). Open Web annotation as collaborative learning. First Monday. https://doi.org/1593460390

Kalir, R. (n.d.). Annotation · MIT Press Open. Retrieved 15 April 2021, from https://mitpressonpubpub.mitpress.mit.edu/annotation

Kalir, R. (2020). Remarking on Annotation. Commonplace. https://doi.org/10.21428/6ffd8432.8b15fafc

Kalir, R., \& Dean, J. (2017a). Web Annotation as Conversation and Interruption. The Disrupted Journal of Media Practice. http://journal.disruptivemedia.org.uk/webannotation-as-conversation-and-interruption/

Kalir, R., \& Dean, J. (2017b). Web Annotation as Conversation and Interruption. The Disrupted Journal of Media Practice. http://journal.disruptivemedia.org.uk/webannotation-as-conversation-and-interruption/

Kalir, R., \& Garcia, A. (2019a). Chapter 1. In Annotation. PubPub. https://mitpressonpubpub.mitpress.mit.edu/pub/926svib6/release/1

Kalir, R., \& Garcia, A. (2019b). Chapter 4. In Annotation. https://mitpressonpubpub.mitpress.mit.edu/pub/iy18elkf/release/1

Kalir, R., \& Garcia, A. (2021a). Annotation. The MIT Press. https://mitpressonpubpub.mitpress.mit.edu/annotation 
Kalir, R., \& Garcia, A. (2021b). Curating a Public Conversation about Annotation.

Commonplace. https://doi.org/10.21428/6ffd8432.3f25b263

Kasprzak, D. M., \& Smyre, T. (2017). Forerunners and Manifold: A Case Study in Iterative Publishing. Journal of Scholarly Publishing, 48(2), 90-98.

https://doi.org/10.3138/jsp.48.2.90

Kember, S. (2014). Opening Out from Open Access: Writing and Publishing in Response to Neoliberalism. Ada: A Journal of Gender, New Media, and Technology.

http://adanewmedia.org/2014/04/issue4-kember/

Kennedy, M. (2016). Open Annotation and Close Reading the Victorian Text: Using Hypothes.is with Students. Journal of Victorian Culture, 21(4), 550-558.

https://doi.org/10.1080/13555502.2016.1233905

Kingsley, D. (2016a, March 3). Is CC-BY really a problem or are we boxing shadows? | Unlocking Research. Unlocking Research. https://unlockingresearch-blog.lib.cam.ac.uk/? $\mathrm{p}=555$

Kingsley, D. (2016b, March 3). Is CC-BY really a problem or are we boxing shadows? / Unlocking Research. https://unlockingresearch-blog.lib.cam.ac.uk/?p=555

Kirschenbaum, M. G. (2007). The Remaking of Reading: Data Mining and the Digital Humanities. 134, 5.

Klein, S. (2020). Understander: A Science Annotator. KFG Notes. https://notes.knowledgefutures.org/pub/annotator/release/3

Knöchelmann, M. (2019). Open Science in the Humanities, or: Open Humanities? Publications, 7(4), 65. https://doi.org/10.3390/publications7040065

Lange, F. (2020). An Online Field Study on Scholarly Journal Annotations. In J. Nantke \& F. Schlupkothen (Eds.), Annotations in Scholarly Editions and Research (pp. 221-248). De Gruyter. https://doi.org/10.1515/9783110689112-011

Larivière, V., Haustein, S., \& Mongeon, P. (2015). The Oligopoly of Academic Publishers in the Digital Era. PLOS ONE, 10(6), e0127502.

https://doi.org/10.1371/journal.pone.0127502

Lessig, L. (2008). Remix: Making art and commerce thrive in the hybrid economy. Penguin Press. 
Lewis, V., Spiro, L., Wang, X., Cawthorne, J. E., \& Council on Library and Information Resources. (2015). Building Expertise to Support Digital Scholarship: A Global Perspective.

Lippincott, S. K. (2016). The Library Publishing Coalition: Organizing libraries to enhance scholarly publishing. 29(2), 186-191. https://doi.org/10.1629/uksg.296

Lujano, I. (2017, January 17). Challenges of the Latin American Open Access Publishing Model. DOAJ News Service. https://blog.doaj.org/2017/01/17/challenges-of-the-latinamerican-open-access-publishing-model/

Lyons, A. P. (2019). Hashtag Syllabus. Contexts, 18(4), 16-21.

https://doi.org/10.1177/1536504219883847

Mandler, P. (2014). Open access: A perspective from the humanities. Insights, 27(2), 166170. https://doi.org/10.1629/2048-7754.89

Marino, M. (2015, June 8). Announcing a New Platform for Collaborative Scholarship of Elit. Electronic Literature Organization. https://eliterature.org/2015/06/announcing-a-newplatform-for-collaborative-scholarship-of-e-lit/

Maxwell, J. W. (2015). Beyond Open Access to Open Publication and Open Scholarship. Scholarly and Research Communication, 6(3), Article 3.

https://doi.org/10.22230/src.2015v6n3a202

McCarty, W. (2020). Making and Studying Notes. In Annotations in Scholarly Editions and Research: Functions, Differentiation, Systematization (pp. 271-298). De Gruyter. https://doi.org/10.1515/9783110689112-013

McGregor, H., \& Guthrie, K. (2015). Delivering Impact of Scholarly Information: Is Access Enough? The Journal of Electronic Publishing, 18(3).

https://doi.org/10.3998/3336451.0018.302

McPherson, T. (2010). Scaling Vectors: Thoughts on the Future of Scholarly Communication. Journal of Electronic Publishing, 13(2).

https://doi.org/10.3998/3336451.0013.208

McPherson, T. (2014). Designing for Difference. Differences. A Journal of Feminist Cultural Studies, 25(1), 177-188. https://doi.org/10.1215/10407391-2420039

McPherson, T. (2017). Feminist in a Software Lab: Difference + Design. Harvard University Press. 
Montgomery, L., Hartley, J., Neylon, C., Gillies, M., \& Gray, E. (2021). Open Knowledge Institutions: Reinventing Universities. The MIT Press.

https://doi.org/10.7551/mitpress/13614.001.0001

Montgomery, L., Hartley, J., Neylon, C., Gillies, M., Gray, E., Herrmann-Pillath, C., Huang, C.-K. (Karl), Leach, J., Potts, J., Ren, X., Skinner, K., Sugimoto, C. R., \& Wilson, K. (2018). Open Knowledge Institutions. https://doi.org/10.21428/99f89a34

Moore, S. A. (2017). A genealogy of open access: Negotiations between openness and access to research. Revue Française Des Sciences de 1' information et de La Communication, 11, Article 11. https://doi.org/10.4000/rfsic.3220

Moretti, F. (2000). Conjectures on World Literature. New Left Review, 1, 54-68.

Odell, J. D., \& Pollock, C. M. J. (2016). Open Peer Review for Digital Humanities Projects: A Modest Proposal [Working Paper]. https://doi.org/10.7912/C2NC7S

Okune, A., Hillyer, R., Chan, L., Albornoz, D., \& Posada, A. (2019). Whose Infrastructure? Towards Inclusive and Collaborative Knowledge Infrastructures in Open Science. In P. Mounier (Ed.), Connecting the Knowledge Commons-From Projects to Sustainable Infrastructure: The 22nd International Conference on Electronic Publishing - Revised Selected Papers. OpenEdition Press. http://books.openedition.org/oep/9072

Perkel, J. M. (2015). Annotating the scholarly web. Nature, 528(7580), 153-154. https://doi.org/10.1038/528153a

Pinto, P. (2021). Annotation as social construction of knowledge. Commonplace. https://doi.org/10.21428/6ffd8432.2751b969

Poslusny, A. (2019, December 8). Digital Technology \& Learning. Issues in Art History. http://annieposlusny.com/uncategorized/digital-technology-learning/

Provo, A. (2019). From index to network: Topic maps in the Enhanced Networked Monographs project. The Indexer: The International Journal of Indexing, 37(1), 13-35. https://doi.org/10.3828/indexer.2019.3

Risam, R. (2014). Rethinking Peer Review in the Age of Digital Humanities. Ada: A Journal of Gender, New Media, and Technology, 4. https://doi.org/10.7264/n3wq0220

Ross-Hellauer, T. (2017). What is open peer review? A systematic review (6:588). F1000Research. https://doi.org/10.12688/f1000research.11369.2 
Ross-Hellauer, T., \& Derrick, G. E. (2019). Decolonising the social sciences and humanities through peer review. https://ressh2019.webs.upv.es/wpcontent/uploads/2019/10/ressh_2019_paper_2.pdf

Ross-Hellauer, T., \& Görögh, E. (2019). Guidelines for open peer review implementation. Research Integrity and Peer Review, 4(1), 4. https://doi.org/10.1186/s41073-019-0063-9

Seatter, L. (2019). Towards Open Annotation: Examples and Experiments. KULA: Knowledge Creation, Dissemination, and Preservation Studies, 3(1), 12. https://doi.org/10.5334/kula.49

Skains, R. L. (2020). Discourse or gimmick? Digital marginalia in online scholarship. Convergence, 26(4), 942-955. https://doi.org/10.1177/1354856519831988

Snijder, R. (2019). The deliverance of open access books: Examining usage and dissemination. Amsterdam University Press. https://library.oapen.org/handle/20.500.12657/25287

Suber, P. (2008, August 2). Gratis and libre open access. SPARC Open Access Newsletter, Issue \#124. https://dash.harvard.edu/bitstream/handle/1/4322580/suber_oagratis.html

Suber, P. (2012). Open access. MIT Press.

Sullivan, D. (2013). Tech Services on the Web: CATMA: Computer Aided Textual Markup \& Analysis; http://www.catma.de/. Technical Services Quarterly, 30(3), 337-338. https://doi.org/10.1080/07317131.2013.788370

The British Academy. (2018). Open access and monographs: Where are we now? https://www.thebritishacademy.ac.uk/documents/83/British_Academy_paper_on_Open_acc ess_and_monographs-May_2018.pdf

The English Association. (2020, May 29). The English Association and University English response to the UK Research and Innovation (UKRI) Open Access consultation. The English Association. https://englishassociation.ac.uk/response-to-the-ukri-open-accessconsultation/

Tulley, C., \& Blair, K. (2009). Remediating the Book Review: Toward Collaboration and Multimodality across the English Curriculum. Pedagogy, 9(3), 441-469. https://doi.org/10.1215/15314200-2009-005 
van den Broeke, G. (2014, October 7). Supporting Open Annotation. Hypothesis. https://web.hypothes.is/blog/supporting-open-annotation/

van Rooyen, S., Black, N., \& Godlee, F. (1999). Development of the Review Quality Instrument (RQI) for Assessing Peer Reviews of Manuscripts. Journal of Clinical Epidemiology, 52(7), 625-629. https://doi.org/10.1016/S0895-4356(99)

Vézina, B. (2020, April 21). Why Sharing Academic Publications Under "No Derivatives" Licenses is Misguided. Creative Commons. https://creativecommons.org/2020/04/21/academic-publications-under-no-derivatives$\underline{\text { licenses-is-misguided/ }}$

W3C Web Annotation Working Group. (n.d.). Retrieved 7 September 2021, from https://via.hypothes.is/https://www.w3.org/annotation/

W3C Web Annotation Working Group. (2017). https://www.w3.org/annotation/

Walkowski, N.-O. (2019). Beyond the Flow: Scholarly Publications During and After the Digital. meson press. https://doi.org/10.14619/1600

Watters, A. (2017, April 26). Un-Annotated. Audrey Watters. http://audreywatters.com/2017/04/26/no-annotations-thanks-bye

Whaley, D. (2016, March 29). Preventing Abuse. Hypothesis. https://web.hypothes.is/blog/preventing-abuse/

Wiley, D. (n.d.). Defining the 'Open' in Open Content and Open Educational Resources. Retrieved 9 August 2021, from https://opencontent.org/definition/

Wissler, L., Almashraee, M., Monett, D., \& Paschke, A. (2014). The Gold Standard in Corpus Annotation. https://doi.org/10.13140/2.1.4316.3523

Zucker, L., Kalir, J., Sprouse, M., \& Dean, J. (2021). Foregrounding the Margins: A Dialogue about Literacy, Learning, and Social Annotation. Teaching/Writing: The Journal of Writing Teacher Education, 10(1). https://scholarworks.wmich.edu/wte/vol10/iss1/10 


\section{Footnotes}

1. According to the Cambridge Dictionary, "Annotation" refers to "a short explanation or note added to a text or image, or the act of adding short explanations or notes" (Cambridge Dictionary, 2021).

2. For an excellent overview of the possibilities and drawbacks of social annotation in open educational sections, which this report doesn' t engage itself with in depth, see Brown and Croft 2020.

3. See https://www.w3.org/annotation/ $\triangleq$

4. Also see Lukas Zimmer's and Anthon Astrom's project Lines as a good example of the ever-expanding book (thanks to Rebekka Kiesewetter for pointing out this project): http://lines.thecafesociety.org $L \leftrightharpoons$

5. Also see the importance of pre-digital forms of (private) note-taking such as index cards and zettelkasten (e.g., https://niklas-luhmann-archiv.de/) (McCarty_2020). 6. Hypothes.is can be configured to store annotation data somewhere else, which is what the HIRMEOS project and publishers such as OpenEdition Books (together with DOAB), Lever Press, and Pressbooks have done (see Part 2 for further details). $\Xi$

7. See for example Audrey Watters' argument on why she decided to explicitly block annotation overlay tools (Watters 2017) in her blog.

8. 
The full list of open peer review traits Ross-Hellauer mentions includes:

Open identities: Authors and reviewers are aware of each other' s identity

Open reports: Review reports are published alongside the relevant article.

Open participation: The wider community are able to contribute to the review process.

Open interaction: Direct reciprocal discussion between author(s) and reviewers, and/or between reviewers, is allowed and encouraged.

Open pre-review manuscripts: Manuscripts are made immediately available (e.g., via pre-print servers like arXiv) in advance of any formal peer review procedures.

Open final-version commenting: Review or commenting on final "version of record" publications.

Open platforms: Review is de-coupled from publishing in that it is facilitated by a different organizational entity than the venue of publication. $\bullet$

9. Fitzpatrick has since repeated this process for her book Generous Thinking: The University and the Public Good, which was available for open or community peer review on the Humanities Commons platform, again using CommentPress. The revised version was published by Johns Hopkins University Press in 2019.

10. Eve notes though that the problems with peer review are social in nature and cannot be fixed by "techno-fetishism" (Eve 2014: 146). There is therefore no guarantee that open peer review will not rehearse the biases of closed review or even lead to new forms of bias. $\_$

11. See https://publicphilosophyjournal.org/overview/and https://publicphilosophyjournal.org/instructions-for-participants/

12. Lawrence Lessig research on remix has also been influential in this context where he refers to remix as a Read/Write (RW) culture, as opposed to a Read/Only (RO) culture (Lessig, 2008, 2).

13. As Suber explains, "Gratis OA removes no permission barriers and libre OA removes one or more permission barriers. (Both of them remove price barriers)" (Suber 2008). 
14. Open source describes a model of peer production in which users are free to access and use (gratis), and modify, reuse, and collaborate on code (libre), for example to build new software following the reusability principles. $\bullet$

15. There are also further options for augmented reality interactions, to bridge the connection between print and digital and enhance print or hybrid publications with digital interactions. $\subseteq$

\section{Citations}

1. Bertino, A. C., \& Staines, H. (2019). Enabling A Conversation Across Scholarly Monographs through Open Annotation. Publications, 7(2), 41. https://doi.org/10.3390/publications7020041

2. McPherson, T. (2010). Scaling Vectors: Thoughts on the Future of Scholarly Communication. Journal of Electronic Publishing, 13(2). https://doi.org/10.3998/3336451.0013.208 3. Kalir, R., \& Garcia, A. (2021). Annotation. Cambridge, Massachusetts: The MIT Press. Retrieved from https://mitpressonpubpub.mitpress.mit.edu/annotation $\subseteq$

4. Lange, F. (2020). An Online Field Study on Scholarly Journal Annotations. In J. Nantke \& F. Schlupkothen (Eds.), Annotations in Scholarly Editions and Research (pp. 221-248). De Gruyter. https://doi.org/10.1515/9783110689112-011

5. van den Broeke, G. (2014). Supporting Open Annotation. Hypothesis. Retrieved from https://web.hypothes.is/blog/supporting-open-annotation/ $\triangleq$

6. Perkel, J. M. (2015). Annotating the scholarly web. Nature, 528(7580), 153-154. https://doi.org/10.1038/528153a $\leftrightharpoons$

7. Montgomery, L., Hartley, J., Neylon, C., Gillies, M., Gray, E., Herrmann-Pillath, C., ... Wilson, K. (2018). Open Knowledge Institutions. MIT Press OA Books. https://doi.org/10.21428/99f89a34

8. Adema, J. (2018). Performative Publications. Media Practice and Education, 19(1), 6881. https://doi.org/10.1080/14682753.2017.1362174

9. Kalir, R., \& Dean, J. (2017). Web Annotation as Conversation and Interruption. The Disrupted Journal of Media Practice. Retrieved from 
http://journal.disruptivemedia.org.uk/web-annotation-as-conversation-and-interruption/

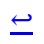

10. Kalir, R., \& Garcia, A. (2019). Chapter 4. In Annotation. Retrieved from https://mitpressonpubpub.mitpress.mit.edu/pub/iy18elkf/release/1

11. Humphreys, A., Spencer, C., Brown, L., Loy, M., \& Snyder, R. (2018). Reimagining the Digital Monograph: Design Thinking to Build New Tools for Researchers. The Journal of Electronic Publishing, 21(1). https://doi.org/10.3998/3336451.0021.102 12. Chenoweth, K. (2018). Derrida' s Margins. Retrieved from https://derridasmargins.princeton.edu/ $\leftrightharpoons$

13. Skains, R. L. (2020). Discourse or gimmick? Digital marginalia in online scholarship. Convergence, 26(4), 942-955. https://doi.org/10.1177/1354856519831988

14. Perkel, J. M. (2015). Annotating the scholarly web. Nature, 528(7580), 153-154. https://doi.org/10.1038/528153a

15. Faulkes, Z. (2014). The Vacuum Shouts Back: Postpublication Peer Review on Social Media. Neuron, 82(2), 258-260. https://doi.org/10.1016/j.neuron.2014.03.032

16. Skains, R. L. (2020). Discourse or gimmick? Digital marginalia in online scholarship. Convergence, 26(4), 942-955. https://doi.org/10.1177/1354856519831988 17. Whaley, D. (2016). Preventing Abuse. Hypothesis. Retrieved from https://web.hypothes.is/blog/preventing-abuse/ 18. Gunn, L. (2016). Involving Page Owners in Annotation. Hypothesis. Retrieved from https://web.hypothes.is/blog/involving-page-owners-in-annotation/

19. Dyson, E. (2017). Keynote. Retrieved from https://www.youtube.com/watch? $\underline{\mathrm{v}=\mathrm{T} \_\mathrm{mTCFFrQ}} \underline{4 \mathrm{~A}} \underline{\underline{ }}$

20. Ahearn, C. (2020). Pathways to PubPub. MIT Press Open. Retrieved from https://mitpressonpubpub.mitpress.mit.edu/pub/pathways/release/1 21. Fyfe, A. (2015). Peer review: not as old as you might think. Times Higher Education (THE). Retrieved from https://www.timeshighereducation.com/features/peer-review-notold-you-might-think 
22. Fyfe, A., Coate, K., Curry, S., Lawson, S., Moxham, N., \& Røstvik, C. M. (2017). Untangling Academic Publishing: A history of the relationship between commercial interests, academic prestige and the circulation of research.

https://doi.org/10.5281/zenodo.546100

23. Fyfe, A. (2015). Peer review: not as old as you might think. Times Higher Education (THE). Retrieved from https://www.timeshighereducation.com/features/peer-review-notold-you-might-think $\subseteq$

24. Godlee, F. (2000). The Ethics of Peer Review. In A. H. Jones \& F. McLellan (Eds.), Ethical Issues in Biomedical Publication. Baltimore, UNITED STATES: Johns Hopkins University Press. Retrieved from http://ebookcentral.proquest.com/lib/coventry/detail.action?docID=3318111 25. Knöchelmann, M. (2019). Open Science in the Humanities, or: Open Humanities? Publications, 7(4), 65. https://doi.org/10.3390/publications7040065 26. Ross-Hellauer, T., \& Derrick, G. E. (2019). Decolonising the social sciences and humanities through peer review. Retrieved from https://ressh2019.webs.upv.es/wpcontent/uploads/2019/10/ressh_2019_paper_2.pdf $\triangleq$ 27. Ross-Hellauer, T. (2017). What is open peer review? A systematic review. https://doi.org/10.12688/f1000research.11369.2

28. Fitzpatrick, K. (2011). Planned obsolescence: publishing, technology, and the future of the academy. New York: New York University Press. Retrieved from https://mcpress.media-commons.org/plannedobsolescence/ $\leftrightharpoons$ 29. Fitzpatrick, K. (2011). Planned obsolescence: publishing, technology, and the future of the academy. New York: New York University Press. Retrieved from https://mcpress.media-commons.org/plannedobsolescence/ $\leftrightharpoons$ 30. Godlee, F. (2000). The Ethics of Peer Review. In A. H. Jones \& F. McLellan (Eds.), Ethical Issues in Biomedical Publication. Baltimore, USA: Johns Hopkins University Press. Retrieved from http://ebookcentral.proquest.com/lib/coventry/detail.action? $\underline{\text { docID }=3318111} \leftrightharpoons$ 31. Eve, M. P. (2013). The Future of Peer Review. Martin Paul Eve. Retrieved from https://eve.gd/2013/03/15/the-future-of-peer-review/ $ヒ$ 
32. Fitzpatrick, K. (2009). Peer-to-Peer Review and the Future of Scholarly Authority. Cinema Journal, 48(2), 124-129. https://doi.org/10.1353/cj.0.0095

33. Fitzpatrick, K., \& Rowe, K. (2010). Keywords for Open Review. LOGOS: The. Journal of the World Book Community, 21(3-4), 133-141.

34. Eve, M. P. (2014). Open Access and the Humanities. Cambridge: Cambridge University Press. $\subseteq$

35. Fitzpatrick, K. (2012). Beyond Metrics: Community Authorization and Open Peer Review. In Debates in the Digital Humanities. University of Minnesota Press. https://doi.org/10.5749/minnesota/9780816677948.003.0046 36. Dougherty, J., \& Nawrotzki, K. (Eds.). (2013). Writing History in the Digital Age. University of Michigan Press. https://doi.org/10.2307/j.ctv65sx57

37. Cohen, P. (2010). Scholars Test Web Alternative to Peer Review. The New York Times. Retrieved from https://www.nytimes.com/2010/08/24/arts/24peer.html 38. Risam, R. (2014). Rethinking Peer Review in the Age of Digital Humanities. Ada New Media. Retrieved from https://adanewmedia.org/2014/04/issue4-risam/ 39. Odell, J. D., \& Pollock, C. M. J. (2016). Open Peer Review for Digital Humanities Projects: A Modest Proposal. https://doi.org/10.7912/C2NC7S $ヒ$ 40. Risam, R. (2014). Rethinking Peer Review in the Age of Digital Humanities. Ada New Media. Retrieved from https://adanewmedia.org/2014/04/issue4-risam/ 41. Dandieu, C., \& HIRMEOS Consortium. (2019). Report on Post-Publication Open Peer Review Experiment. https://doi.org/10.5281/zenodo.3275651 42. Lippincott, S. K. (2016). The Library Publishing Coalition: organizing libraries to enhance scholarly publishing, 29(2), 186-191. https://doi.org/10.1629/uksg.296 43. Cullen, D., \& Bell, A. (2018). The Social Text and Networked Knowledge: New Modes of Scholarly Book Publishing in Indigenous Studies. Journal of Scholarly Publishing, 49(2), 193-212. https://doi.org/10.3138/jsp.49.2.193 44. Vézina, B. (2020). Why Sharing Academic Publications Under "No Derivatives" Licenses is Misguided. Creative Commons. Retrieved from https://creativecommons.org/2020/04/21/academic-publications-under-no-derivatives$\underline{\text { licenses-is-misguided/ }} \triangleq$ 
45. Suber, P. (2012). Open access. Cambridge, Mass: MIT Press. $\bullet$ 46. Moretti, F. (2000). Conjectures on World Literature. New Left Review, (1), 54-68. 47. Kirschenbaum, M. G. (2007). The Remaking of Reading: Data Mining and the Digital Humanities (Vol. 134, p. 5). Baltimore, Md. 48. Mandler, P. (2014). Open access: a perspective from the humanities. Insights, 27(2), 166-170. https://doi.org/10.1629/2048-7754.89 49. Kingsley, D. (2016). Is CC-BY really a problem or are we boxing shadows? |textbar Unlocking Research. Unlocking Research. Retrieved from https://unlockingresearchblog. lib.cam.ac.uk/?p=555

50. The British Academy. (2018). Open access and monographs: Where are we now? Retrieved from https://www.thebritishacademy.ac.uk/documents/83/British_Academy_paper_on_open_a ccess_and_monographs-May_2018.pdf $\triangleq$

51. Arts and Humanities Alliance. (2019). Plan S Consultation response from the Arts and Humanities Alliance. Retrieved from http://artsandhums.org/news-2/plan-sconsultation-response/ $\triangleq$

52. Hall, G. (2016). Pirate Philosophy: For a Digital Posthumanities. Cambridge, Massachusetts: MIT Press. $\_$ 53. Adema, J. (2021). Living Books: Experiments in the Posthumanities. Cambridge, MA, USA: MIT Press. $\leftrightarrows$

54. Christen, K. A. (2012). Does Information Really Want to be Free? Indigenous Knowledge Systems and the Question of Openness. International Journal of Communication, 6, 24. Retrieved from https://ijoc.org/index.php/ijoc/article/view/1618 55. Okune, A., Hillyer, R., Chan, L., Albornoz, D., \& Posada, A. (2019). Whose Infrastructure? Towards Inclusive and Collaborative Knowledge Infrastructures in Open Science. In P. Mounier (Ed.), Connecting the Knowledge Commons - From Projects to Sustainable Infrastructure: The 22nd International Conference on Electronic Publishing - Revised Selected Papers. Marseille: OpenEdition Press. Retrieved from http://books.openedition.org/oep/9072 $ヒ$ 
56. Adema, J., \& Hall, G. (2013). The Political Nature of the Book: On Artists' Books and Radical Open Access. New Formations, 78(78), 138-156.

https://doi.org/10.3898/NewF.78.07.2013

57. Harnad, S. (2012). Open Access: Gratis and Libre. Open Access Archivangelism.

Retrieved from http://openaccess.eprints.org/index.php?/archives/885-Open-Access-

Gratis-and-Libre.html $\leftrightharpoons$

58. Moore, S. A. (2017). A genealogy of open access: negotiations between openness and access to research. Revue Française Des Sciences de 1' information et de La

Communication, (11). https://doi.org/10.4000/rfsic.3220

59. Lujano, I. (2017). Challenges of the Latin America Open Access Publishing Model.

DOAJ News Service. Retrieved from https://blog.doaj.org/2017/01/17/challenges-of-thelatin-american-open-access-publishing-model/ $\leftrightharpoons$

60. Kasprzak, D. M., \& Smyre, T. (2017). Forerunners and Manifold: A Case Study in Iterative Publishing. Journal of Scholarly Publishing, 48(2), 90-98.

$\underline{\text { https://doi.org/10.3138/jsp.48.2.90 }}$

61. Ball, C. E., \& Eyman, D. (2015). Editorial Workflows for Multimedia-Rich

Scholarship. Journal of Electronic Publishing, 18(4).

https://doi.org/10.3998/3336451.0018.406

62. Hall, G. (2013). The Unbound Book: Academic Publishing in the Age of the Infinite Archive. Journal of Visual Culture, 12(3), 490-507.

https://doi.org/10.1177/1470412913502032

63. Adema, J. (2015, May). Knowledge Production Beyond The Book? Performing the Scholarly Monograph in Contemporary Digital Culture. Coventry. Retrieved from http://curve.coventry.ac.uk/open/items/8222ccb2-f6b0-4e5f-90de-f4c62c77ac86/1/ 64. Adema, J., Hall, G., \& Cota, G. M. (2021). Combinatorial Books - Gathering Flowers Part I. COPIM. https://doi.org/10.21428/785a6451.d3ecc6cc $ヒ$

65. Arbuckle, A., Meneses, L., \& Siemens, R. (2019). Introduction, Beyond Open: Implementing Social Scholarship. KULA: Knowledge Creation, Dissemination, and Preservation Studies, 3. https://doi.org/10.5334/kula.55

66. Arbuckle, A. (2019). Open+: Versioning Open Social Scholarship. KULA: Knowledge Creation, Dissemination, and Preservation Studies, 3. https://doi.org/10.5334/kula.39 
67. Hyde, A. (2016). Facilitators not Editors, Collaborators not Writers. Adam Hyde. Retrieved from https://www.adamhyde.net/facilitators-not-editors-collaborators-not$\underline{\text { writers } /} \leftrightarrows$

68. McHardy, J. (2021). Tentative Florilegium: Experiments \& Recipes for ReWriting Books. COPIM. https://doi.org/10.21428/785a6451.840fc9e5 $\leftrightharpoons$ 69. Maxwell, J. W. (2015). Beyond Open Access to Open Publication and Open Scholarship. Scholarly and Research Communication, 6(3). https://doi.org/10.22230/src.2015v6n3a202 70. McGregor, H., \& Guthrie, K. (2015). Delivering Impact of Scholarly Information: Is Access Enough? The Journal of Electronic Publishing, 18(3). https://doi.org/10.3998/3336451.0018.302 71. Fitzpatrick, K. (2007). CommentPress: New (Social) Structures for New (Networked) Texts. The Journal of Electronic Publishing, 10(3). https://doi.org/10.3998/3336451.0010.305 72. Adema, J., \& Hall, G. (ongoing). liquidbooks / The Academia_edu Files. Retrieved from

http://liquidbooks.pbworks.com/w/page/106236504/The\%20Academia_edu\%20Files 73. Lyons, A. P. (2019). Hashtag Syllabus. Contexts, 18(4), 16-21. $\underline{\text { https://doi.org/10.1177/1536504219883847 }}$

74. Graziano, V., Mars, M., \& Medak, T. (2019). Learning from \#Syllabus. Humanities Commons. https://doi.org/10.17613/NKTX-KA69

75. El Khatib, R., Seatter, L., Hajj, T. E., Leibel, C., Arbuckle, A., Siemens, R., ... Groups, the ETCL and INKE Research. (2019). Open Social Scholarship Annotated Bibliography. KULA: Knowledge Creation, Dissemination, and Preservation Studies, 3, 24-24. https://doi.org/10.5334/kula.58

76. Adema, J. (2021). Versioning and Iterative Publishing. Commonplace. https://doi.org/10.21428/6ffd8432.42408f5b $\leftrightharpoons$ 77. Marino, M. C., \& Ciston, S. (2021). How to Fork a Book: The Radical Transformation of Publishing. Mark C. Marino. Retrieved from https://markcmarino.medium.com/howto-fork-a-book-the-radical-transformation-of-publishing-3e1f4a39a66c $ヒ$ 
78. Marino, M. (2015). Announcing a New Platform for Collaborative Scholarship of E-lit - Electronic Literature Organization. Electronic Literature Organization. Retrieved from https://eliterature.org/2015/06/announcing-a-new-platform-for-collaborativescholarship-of-e-lit/

79. Kirschenbaum, M. G. (2007). The Remaking of Reading: Data Mining and the Digital Humanities (Vol. 134, p. 5). Baltimore, Md. $\leftrightarrows$

80. Walkowski, N.-O. (2019). Beyond the Flow: Scholarly Publications During and After the Digital. DE: meson press. Retrieved from https://doi.org/10.14619/1600

81. Provo, A. (2019). From index to network: topic maps in the Enhanced Networked Monographs project. The Indexer: The International Journal of Indexing, 37(1), 13-35. https://doi.org/10.3828/indexer.2019.3

82. Christie, A. (2014). Interdisciplinary, Interactive, and Online: Building open communication through multimodal scholarly articles and monographs. Scholarly and Research Communication, 5(4). https://doi.org/10.22230/src.2014v5n4a190 $\triangleq$ 